\title{
Article
}

\section{Isolation and Studies on Bacterial Endophytes from Two Venezuelan Rice Cultivars}

\author{
Felix Moronta-Barrios ${ }^{1-2}$, Fabrizia Gionechetti ${ }^{3}$, Alberto Pallavicini ${ }^{3}$, Edgloris Marys ${ }^{2}$, and \\ Vittorio Venturi ${ }^{* *}$. \\ 1 Bacteriology Group, International Center of Genetic Engineering and Biotechnology ICGEB, Trieste, Italy. \\ felix.moronta@icgeb.org \\ 2 Laboratory of Plant Biotechnology and Virology. Center of Microbiology and Cell Biology. Venezuelan \\ Institute of Scientific Research IVIC, Caracas, Venezuela. \\ 3 Department of Life Science, University of Trieste, Italy. \\ * Correspondence: vittorio.venturi@icgeb.org; Tel.: +39040375719
}

\begin{abstract}
Rice is currently the most important food crop in the world and we are only just beginning to study the bacterial associated microbiome. It is of importance to perform screenings of the core rice microbiota and also to develop new plant-microbe models and simplified communities for increasing our understanding about the formation and function of its microbiome. In order to begin to address this aspect, we have performed the isolation of hundreds bacterial isolates obtained from endorhizosphere of two rice cultivars from Venezuela. The validation of plant-growth promoting bacterial activities in vitro has led us to select and characterize 15 isolates for in planta studies such as germination test, endophytism ability and plant growth promotion. Consequently, a set of 10 isolates was selected for the set-up of an endophytic consortium as a simplified model of the natural rice bacterial endomicrobiota. Upon inoculation, the colonization and abundance of each strain within the rice roots was tracked by a culture-independent technique in gnotobiotic conditions in a 30 days period. Four strains belonging to Pseudomonas, Agrobacterium and Delftia genera have shown a promising capacity for colonizing and coexistence in root tissues. On the other hand, a bacterial community taxonomic profiling of the rhizosphere and the endorhizosphere of both cultivars were obtained and are discussed. This study is part of a growing body of research on core crops microbiome and simplified microbiomes, which strengthens the formation process of the endophytic community leading to a better understanding of the rice microbiome.
\end{abstract}

Keywords: rice; endophyte; sustainable agriculture; plant microbiome; simplified bacterial community; syncomm; taxonomic profiling; core plant microbiome.

\section{Introduction}

Rice is the staple food for more than a half of the world population and its production is dependent on chemical fertilizers and pesticides [1] which are in part responsive for global warming and groundwater pollution [2]. To meet the world demand of rice it is imperative to find environmentally sound ways that supplement the need for fertilizers [3]. The use of microbial inoculants is attractive because they can complement and mitigate the use of the agrochemicals ensuring a healthier environment [2]. 
Microorganisms play an important role in agricultural systems where they live in close association with plants and can exert different kinds of positive effects on the crop health and growth [4]. The effects of this microbiota include (i) increased nutrient availability (biofertilization), (ii) the ability to compete, eliminate or reduce the effect of potential pathogens (antagonism), (iii) the ability to chemically stimulate the growth and/or tolerance of the host to abiotic stress (phytostimulation) and (iv) the ability to inactivate or degrade existing toxic substances in the soil (detoxification) [5]-[7]. Rhizosphere bacteria which live in the soil that is in intimate contact with the roots and are able to perform one or more of these functions are known as plant-growth promoting rhizobacteria or PGPR [8]. Some rhizosphere bacteria are capable of penetrating the surface of the roots and colonize the internal tissues of the root, a niche also known as endorhizosphere and these bacteria are called endophytes [9]. Bacterial endophytes overcome plant defenses and establish themselves as permanent inhabitants of internal tissues without causing harm to the host plant [10]. It is believed that bacteria colonizing the interior plant tissues could interact closely with the host having less competition for nutrients and living in a more protected environment [11]. Although the composition of the endophytic microbiota of various plants is now being studied [10][12][13] including rice plants [14]-[16], our knowledge of the endophytic bacterial ecology remains limited and the identification and characterization of novel beneficial endophytes is needed. In addition, most studies involving PGPR and endophytic bacteria are mostly restricted to monostrain set-ups under laboratory conditions [17], and our understanding of the effect of entire microbial communities to plant growth remains at large unexplored. The use of beneficial plant associated bacteria as microbial inoculants in agriculture has been considered and studied for many years however they are still primarily being used for organic farming [18]. Due mainly to the new and cheap technologies of next generation sequencing, there is now a new fast growing interest to develop novel microbial inoculants for which can be used at large scale agriculture thus reducing the use of chemical additives. Microbial bioinoculants face competition with the native soil microbiota and also need to withstand the natural abiotic conditions of soil and weather. A reductionist approach using simplified communities as models could facilitate the understanding of the microbial and plant-microbes interactions that occur in the soil [19].

Following these considerations, we have undertaken the $16 \mathrm{~S}$ rDNA taxonomic bacterial profiling of the rhizosphere and endorhizosphere of two Venezuelan rice cultivars, Pionero 2010 FL and DANAC SD20A. Fifteen putative bacterial endophytes were then isolated from surface-sterilized sampled rice roots and further studied. We have also performed inoculation of rice seedlings with a simplified community composed by 10 of the isolates and we have tracked them in the course of 30 days in greenhouse cultivation. The results obtained suggest that the isolates possess PGP potential and 4 were able to significantly colonize together the endorhizosphere of rice indicating possible cooperation and ability to form a stable multispecies community. We believe this approach can be useful in the development of microbial solutions for a more sustainable agriculture.

\section{Materials and Methods}

\subsection{Sample collection and isolation of bacteria from rhizosphere and endorhizosphere}

Three rice plants of cultivars Pionero 2010 FL (88 days after planting) and DANAC SD20A (90 days after planting) were collected in April 2014 from two fields in Acarigua (Portuguesa, Venezuela) and 
packaged in sterile bags and cooled at $4{ }^{\circ} \mathrm{C}$ before bacterial isolation. Five grams of roots with the adherent soil were gently vortexed for 5 minutes in $20 \mathrm{~mL}$ of sterile saline solution $(0.85 \% \mathrm{NaCl})$ and the rhizospheric soil suspensions were serially diluted and plated $(100 \mu \mathrm{L})$ on LB agar with cycloheximide $\left(50 \mathrm{mg} / \mathrm{ml}^{-1}\right)$ for determining the amount of rhizospheric colony-forming units (RCFU). The same 5 grams of rice roots were then surface sterilized in $70 \%$ ethanol for 1 minute followed by $1,2 \%$ hypoclorite for 15 minutes with agitation and finally washed 6 times with sterile distilled water. The extent of the sterilization was verified by plating $100 \mu \mathrm{L}$ of the final wash on LB plates before proceeding maceration. Sterilized roots were then macerated using sterile mortar and pestle in $10 \mathrm{~mL}$ of $0.85 \% \mathrm{NaCl}$ sterile solution and different dilutions were plated on $\mathrm{LB} /$ cycloheximide plates for determining the amount of putative endophytic colony-forming units (ECFU). The plates were incubated at $30^{\circ} \mathrm{C}$ for 2 days. Independent ECFU showing distinct colony morphology were picked and streaked again on LB plates to ensure purity of the culture. The remnants of macerated roots and rhizospheric soil suspensions were then used for DNA extraction.

\subsection{Non-cultivable bacterial diversity of rhizosphere and endorhizosphere}

The rhizospheric and endorhizospheric DNA from the two rice cultivars was extracted using Soilmaster DNA Extraction Kit (Epicentre, USA) following the manufacturer's guidance. The quantity and quality of the DNA was assessed with Nanodrop (Thermo Fisher Scientific, USA) and electrophoresis in agarose gel 0,7\%. The extracted DNA was used as template for the first amplification of V4 variable region of the 16S rRNA by PCR primers 515F [20], 802R [21], 806R [20] tailed with two different GC rich sequences enabling barcoding with a second amplification. The primary amplification take advantage of rice specific V4 blocking mitochondrial and chloroplast primers to increase amplification of prokaryotic sequences [22].

Each sample was amplified in triplicate in $20 \mu \mathrm{L}$ volume reaction containing $8 \mu \mathrm{L}$ HotMasterMix 5Prime (Quanta Bio, USA), 0,4 $\mu \mathrm{L}$ BSA 20X, $1 \mu$ EvaGreen $^{\mathrm{TM}}$ 20X (Biotium, USA), 0,5 $\mu \mathrm{L}$ 515F primer $(10 \mu \mathrm{M}$ modified with unitail 1$), 0,25 \mu \mathrm{L} 802 \mathrm{R}$ primer $(10 \mu \mathrm{M}$ modified with unitail 2$), 0,25$ $\mu \mathrm{L}$ 806R primer (10 $\mu \mathrm{M}$ modified with unitail 2), 0,5 $\mu \mathrm{L}$ MitoBlk_515F V4 mithocondrial blocking primer $\left(100 \mu \mathrm{M}, 5^{\prime}\right.$ - TCCCCATGCTTTCGCACCCCA/3SpC3/), 0,5 $\mu \mathrm{L}$ ChloBlk_806R V4 chloroplast blocking primer $\left(100 \mu \mathrm{M}, 5^{\prime}\right.$-GTCTCTAATCCCATTTGCTCC/3SpC3/) and $2 \mu \mathrm{L}$ (10-50 ng) of DNA template. The PCR amplifications were performed with CFX 96 ${ }^{\mathrm{TM}}$ PCR System (Bio-Rad, USA) with 34 cycles of $94{ }^{\circ} \mathrm{C}$ for $20 \mathrm{~s}, 52{ }^{\circ} \mathrm{C}$ for $20 \mathrm{~s}, 65^{\circ} \mathrm{C}$ for $40 \mathrm{~s}$ and a final extension of $65^{\circ} \mathrm{C}$ for $2 \mathrm{~min}$.

The second PCR amplification (switch PCR) is required to attach the barcodes and was performed using a forward primer with the A adaptor, a sample-specific $10 \mathrm{bp}$ barcode and the tail of the primary PCR primers, and a reverse primer with the P1 adaptor sequence and the reverse tail. The reaction was performed in $25 \mu \mathrm{L}$ volume containing $10 \mu \mathrm{L}$ HotMasterMix 5Prime, 1,25 $\mu \mathrm{L}$ EvaGreen $^{\mathrm{TM}} 20 \mathrm{X}, 1,5 \mu \mathrm{l}$ barcoded primer $(10 \mu \mathrm{M}), 1 \mu \mathrm{l}$ of the first PCR product with the following conditions: 8 cycles of $94^{\circ} \mathrm{C}$ for $10 \mathrm{~s}, 60^{\circ} \mathrm{C}$ for $10 \mathrm{~s}, 65^{\circ} \mathrm{C}$ for $40 \mathrm{~s}$ and a final extension of $72{ }^{\circ} \mathrm{C}$ for 3 $\min$.

All the amplicons were checked for their quality and size by agarose gel electrophoresis and pooled together in equimolar amounts. The library was purified by the E-Gel® SizeSelect ${ }^{\mathrm{TM}}$ (Invitrogen, 
USA) and verified the size and the amount with Agilent 2100 Bioanalyzer and Quibit Fluorometer (Thermo Fisher Scientific).

For sequencing the library was submitted to emulsion PCR on the Ion OneTouch ${ }^{\mathrm{TM}} 2$ system using the Ion PGM ${ }^{\mathrm{TM}}$ Template Hi-Q OT2 View (Life Technologies, USA) according to the manufacturer's instructions. Ion sphere particles (ISP) were enriched using the E/S module. Resultant live ISPs were loaded and sequenced on an Ion 316 chip (Life Technologies).

\subsection{Plant-growth promoting activities}

Eighty-seven putative bacterial endophytes or EUFC were tested for indole-3-acetic acid (IAA) production in vitro. The bacterial cultures were grown in LB broth amended with tryptophan (100 $\mu \mathrm{g} / \mathrm{mL})$ at $30^{\circ} \mathrm{C}$ for 4 days. The cells were sedimented by centrifugation and the supernatant $(2 \mathrm{~mL})$ was mixed with $4 \mathrm{~mL}$ of Salkowsky reagent ( $50 \mathrm{~mL}, 35 \%$ perchloric acid, $1 \mathrm{~mL} 0.5 \mathrm{M} \mathrm{FeCl} 3$ solution) and incubated in darkness for $30 \mathrm{~min}$. The appearance of a red-pink color indicated IAA production and OD $530 \mathrm{~nm}$ was recorded [23]. The concentration of IAA produced by cultures was measured with a calibration graph of commercial IAA obtained in the range of $10-100 \mathrm{mg} / \mathrm{mL}$ and plotted in relation to the dry bacterial biomass. Fifteen bacterial isolates positive for the IAA production were chosen for further plant-growth promoting tests. Phosphate solubilization was determined by growing bacteria on Pikovskaya agar [24]. The 1-aminocyclopropane-1-carboxylate (ACC) deaminase activity was determined as described by [25], comparing the growth of bacteria on M9, M9 without N source and M9 with $30 \mu \mathrm{mol}$ of ACC as sole N source. The production of volatile hydrogen cyanide (HCN) was estimated qualitatively according to [26]. N-acyl homoserine lactone quorum sensing signal assays were carried out as using Chromobacterium violaceum CV026 and C. violaceum CV017 as biosensors [27]. Motility assay was performed as described by [28]. The exopolysacharide production was assessed culturing the isolates on yeast extract mannitol medium as described in [29]. The lipolytic activity was determined on $1 / 6$ TSA medium amended with $1 \%$ tributyrin [30] and proteolytic activity on 1/6 TSA medium amended with $2 \%$ of powder milk [31]. The antibacterial activity against rice pathogens (Dickeya zea, Pseudomonas fuscovaginae and Xanthomonas oryzae) was carried out plating the bacterial isolates on a bacterial lawn seeded with the pathogen.

\subsection{Identification of selected isolates}

Bacterial cells from $1 \mathrm{~mL}$ of overnight cultures (in $2 \mathrm{~mL}$ of LB medium) were sedimented by centrifugation and resuspended in sterile PSB $0.5 \mathrm{~mL}$. The cells were boiled for 3 minutes, cooled in ice 3 minutes and centrifuged at maximum speed for 5 minutes. The supernatants were used as template in PCR reactions for amplyfing $16 \mathrm{~S}$ rDNA gene with the universal oligonucleotides $\mathrm{fD} 1$ and rP2 in 30 cycles of $95^{\circ} \mathrm{C} 30$ seconds, $57^{\circ} \mathrm{C} 30$ seconds and $72{ }^{\circ} \mathrm{C} 30$ seconds with Taq DNA Polymerase (Promega, Madison, WI, USA). The PCR products were purified with EuroGOLD Gel Extraction Kit (EuroClone, Milan, Italy) following manufacturers' instructions and sequenced with universal oligos 518F and 800R (Macrogen, Seoul, Korea) yielding $>1500$ bp rDNA sequences. The Blastn (NCBI) allowed the identification of the genera and in certain cases even the species. The online software Phylogeny [32] was used for determining the phylogenetic relationships between the isolates. The isolates were deposited in the Venezuelan Centre of Culture Collection (Institute of 
Experimental Biology, Central University of Venezuela, Caracas) and the 16S rDNA sequences of the isolates were deposited in GeneBank (NCBI) database under accession numbers KY867521 to 36.

\subsection{Generation of rifampicin spontaneous resistant mutants}

Single colonies of endophytic isolates were grown on $5 \mathrm{~mL}$ of LB medium for $24 \mathrm{~h}$ at $30{ }^{\circ} \mathrm{C}$. and aliquots of $100 \mathrm{uL}$ were then plated on LB agar containing rifampicin (Rif) $100 \mu \mathrm{g} / \mathrm{mL}$ and incubated $48 \mathrm{~h}$ at $30^{\circ} \mathrm{C}$. Single rifampicin resistant colonies were re-streaked on LB Rif, stored at $-80^{\circ} \mathrm{C}$ and used for in planta experiments.

\subsection{Germination test, endophytism and plant-growth promotion assay}

Rice seeds (Baldo cultivar) were surface sterilized for 30 minutes with $15 \%$ hypochlorite solution and then rinsed six times with sterile water. Fifty sterilized seeds were germinated in a petri dish containing $20 \mathrm{~mL}$ sterilized water plus $500 \mu \mathrm{L}$ of an overnight culture of each strain (in $1 \mathrm{~mL}$ of LB medium), separately. The plates with seeds were kept in the dark at $30{ }^{\circ} \mathrm{C}$ for 4 days, before determining the germination rate of 10 groups of 5 germinated seeds. Individual seedlings were then transferred to a $50 \mathrm{~mL}$ tube containing $35 \mathrm{ml}$ of semisolid $(0.25 \%$ agar) $1 / 2$ Hoagland solution [33] amended with $0.5 \mathrm{~mL}$ of an overnight bacterial culture and incubated at $28{ }^{\circ} \mathrm{C}, 75 \%$ humidity, $16 \mathrm{~h} / 8 \mathrm{~h}$ light-dark cycles. The seedlings were watered every two days using $1 / 10$ Hoagland solution. After 15 days, the inoculated plant roots were washed abundantly with tap water, dried with paper, separated from the aerial parts (cutting just below the cotyledon) and weighed. The root surface sterilization was performed as explained above and checked by plating the centrifuged sediment of the last wash $(30 \mathrm{~mL})$ on LB Rif $100 \mu \mathrm{g} / \mathrm{mL}$. Roots were macerated in sterile pestle and mortar with 3 $\mathrm{mL}$ of PBS sterile solution and $100 \mu \mathrm{L}$ of the macerate was plated on $\mathrm{LB} /$ Rif plates, incubated at $30^{\circ} \mathrm{C}$ for $48 \mathrm{~h}$. The CFU of recovered bacteria were counted and the number of the putative bacterial endophytes was calculated as CFU per gram of root. A control group of plants without bacteria was included. The data was statistically analyzed (paired-sample $t$-test, confidence interval $95 \%$ ) using Graph Pad Prism version 5.0a.

\subsection{Simplified community colonization assay}

10 bacterial strains were cultured for $48 \mathrm{~h}$ at room temperature in $10 \mathrm{~mL}$ of LB medium and diluted to $\mathrm{OD}_{600 \mathrm{~nm}}$ of 2.0. The cells were then sedimented by centrifugation, washed with sterile $10 \mathrm{~mL}$ PBS and resuspended in $3 \mathrm{ml}$ PBS. $2 \mathrm{~mL}$ of each bacterial/PBS suspension were mixed and finally $30 \mathrm{mls}$ of PBS was added bringing the final volume to $50 \mathrm{~mL} .2 \mathrm{~mL}$ of this mixed suspension was used for DNA extraction and the remaining $48 \mathrm{~mL}$ were added to $800 \mathrm{~mL}$ of semisolid $1 / 2$ Hoagland solution. A control without bacteria (only with LB broth) was included. One-week-old Baldo rice individual seedlings (sterilized and germinated as described above) were transferred to $40 \mathrm{~mL}$ (in Falcon tubes) of this community-containing semisolid Hoagland solution incubated and watered as described above. Three plants from the control and the treatment were recovered at 10, 20 and 30 days after planting. The roots and aerial parts were separated, and weighed. The roots were then sterilized and macerated with liquid nitrogen. The resulting root powder was used DNA extraction and the library was constructed and sequenced exactly as described in Material and Methods 2.2. 
6 of 25

\subsection{Data analysis}

We used CloVR 1.0 RC9 [34] on the Amazon Elastic Compute Cloud (EC2) to run the QIIME workflow 'pick_otus_through_otu_tables.py' [35]. Within the QIIME workflow: (i) we set the minimum and maximum sequence length to 150 and $350 \mathrm{bp}$, respectively, the maximum homopolymer length to $8 \mathrm{bp}$ and maximum number of ambiguous calls to zero; (ii) clustering was performed using UCLUST with a nucleotide sequence identity threshold within each cluster at $97 \%$ and alignment against the Greengenes 16S database with PyNAST; (iii) taxonomy assignment of each OTU-representing sequence through the RDP classifier with a confidence threshold of 0.8 .

\section{Results}

3.1 Biodiversity of Venezuelan rice rhizosphere and endorhizosphere communities by culture independent methods

In order to obtain a picture of the taxonomic diversity of the two Venezuelan rice cultivars, the population of the non-culturable rhizospheric and endorhizospheric bacterial community was assessed in 6 plants that were harvested from two fields, 3 plants belonging to Pionero 2010 FL cultivar and the other 3 to DANAC SD20A cultivar. The total DNA from rhizosphere and endorhizosphere was extracted for performing 16S rDNA amplicon library sequencing. We obtained 326496 high-quality reads and the reads count per sample was 81171 and 175530 for the rhizosphere and endorhizosphere of Pionero 2010 FL cultivar respectively, and 20421 and 49374 reads for the rhizosphere and endorhizosphere of DANAC SD20A cultivar respectively. After the removal of plant-derived and singletons OTUs, the high-quality reads were clustered in 383 OTUs using > 97\% sequence identity as the cutoff.

Microbiome analysis by phylum distribution and frequency (expressed as \% on the total number of OTUs) is summarized in Figure 1. Representatives of Proteobacteria, the most abundant phylum, were $71 \%$ to $87 \%$ of the total OTUs. Among them, Gammaproteobacteria was most abundant, followed by Betaproteobacteria and Alfaproteobacteria. Representatives of Deltaproteobacteria and Epsilonproteobacteria were not detected in the endorhizospheres. Other abundant phyla were Bacteroidetes, which were nearly equally distributed among the samples with the exception of DANAC SD20A endorhizosphere which represented half of the total $(13.2 \%, 13.1 \%, 15.1 \%$ and 7.4 $\%)$. Verrucomicrobia were enriched in the endorhizosphere of Pionero 2010 FL whereas Actinobacteria, Cyanobacteria, Fibrobacteres and Spirochaetes were equally distributed among the samples. Acidobacteria was only detected in the rhizosphere, as well as Chloroflexi, Nitrospirae and Planctomycetes phyla. 


\section{Pionero 2010 FL DANAC SD20A}

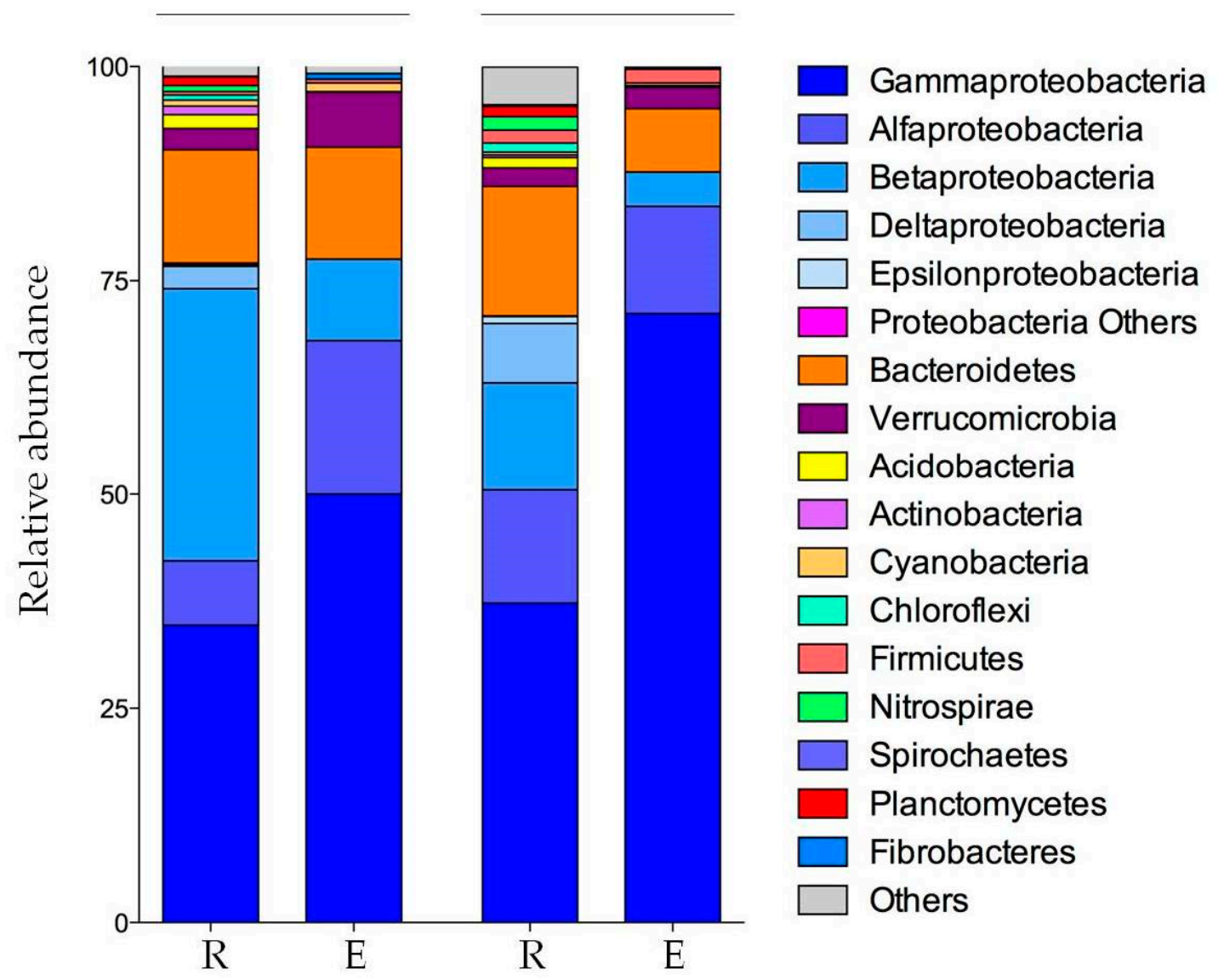

Figure 1. Frequency distribution of the bacterial phyla in the rhizosphere (R) and endorhizosphere (E) of the sampled rice roots. Bar graphs of the taxonomic annotation of bacterial reads among the distribution of the most abundant phyla. The total number of reads obtained for each sample were: Pionero 2010 FL, $n(R)=100732$, n(E) = 198925; DANAC SD20A, n(R) = 34060, n(E) $=80680$.

As expected, the snapshot of the total bacterial community showed a greater abundance and diversity of bacterial species in the rhizosphere than in the endorhizosphere. The Pionero $2010 \mathrm{FL}$ rhizosphere was 1.7X more diverse than its endorhizosphere (ENS 72 vs. 42 , respectively) and the DANAC SD20A rhizosphere possessed 11.9X more species than its endorhizosphere (ENS 250 vs. 21, respectively). The rhizosphere of DANAC SD20A cultivar was colonized by a larger bacterial community than that of Pionero 2010 FL, as demonstrated by the richness and diversity estimators shown in Table 1. 
Table 1. Richness and diversity estimators. The number of observed sequences (Sobs) and estimated richness (Chao, ACE), diversity (Simpson, Shannon and Effective number of species ENS) for Pionero FL2010 and SD20A rice cultivars microbiota, using $97 \%$ 16S rRNA gene sequence similarity cutoffs, are listed. R, rhizosphere; E, endorhizosphere.

\begin{tabular}{cccccccc} 
& & \multicolumn{3}{c}{ Richness estimator } & \multicolumn{3}{c}{ Diversity estimator } \\
\cline { 3 - 7 } & & $S_{\text {obs }}$ & Chao & ACE & Simpson & Shannon & ENS \\
\hline Pionero FL2010 & R & 1497 & 1549.6 & 1586.8 & 0.078 & 4.28 & 72 \\
& E & 794 & 825.5 & 855.2 & 0.089 & 3.74 & 42 \\
\hline \multirow{2}{*}{ SD20A } & R & 1620 & 1663.4 & 1706.7 & 0.014 & 5.52 & 250 \\
& E & 562 & 635.6 & 651.2 & 0.148 & 3.06 & 21 \\
\hline
\end{tabular}

383 OTUs in total were identified and their distribution within the samples is summarized in Figure 2. The Pionero 2010 FL cultivar microbiota was composed by 73 and 52 OTUs exclusively detected in the rhizosphere and in the endorhizospre, respectively. 51 OTUs on the other hand, were detected in both compartments (Figure 2A). Among the species detected in both compartments, which corresponded to the $86.46 \%$ of the reads, Cellvibrio sp., P. pseudoalcaligenes, Opitutus sp., Agrobacterium sp., Pedobacter sp. and Variovorax sp., were significantly enriched in the endorhizosphere, while Pseudomonas sp., Limnobacter sp., Methylotenera mobilis and Pseudomonas veronii were enriched in the rhizosphere. The rest of the 41 OTUs were more or less equally represented in both compartments. The bacteria Microvirgula aerodenitrificans and Caulobacter sp. were the most abundant bacteria found exclusively in the endorhizosphere and Kaistobacter sp. and P. stutzeri were the most abundant ones in the rhizosphere. The DANAC SD20A microbiota was composed by 135 and 51 OTUs exclusively detected in the rhizosphere and in the endorhizosphere, respectively, and 63 OTUs that were detected in both compartments (Figure 2B). Among the species detected in both compartments which corresponded to the $80.42 \%$ of the reads, the following genera were highly enriched in the endorhizosphere: Cellvibrio sp., Caulobacter sp., Rhodoferax sp., $P$. pseudoalcaligenes, Opitutus sp., Agrobacterium sp., Asticcacaulis sp. and Shewanella sp. The rest of the 55 OTUs were more or less equally represented in both compartments. The bacteria Azospirillum massiliensis, Acintobacter lwoffii and Citrobacter sp., were the most abundant in the 51 OTUs group detected exclusively in the endorhizosphere, while Halothiobacillus sp., Methylophaga sp., Arenimonas sp., Thiobacillus sp., and Limnobacter sp., were the most abundant ones in the 135 OTUs group detected exclusively in the rhizosphere. 

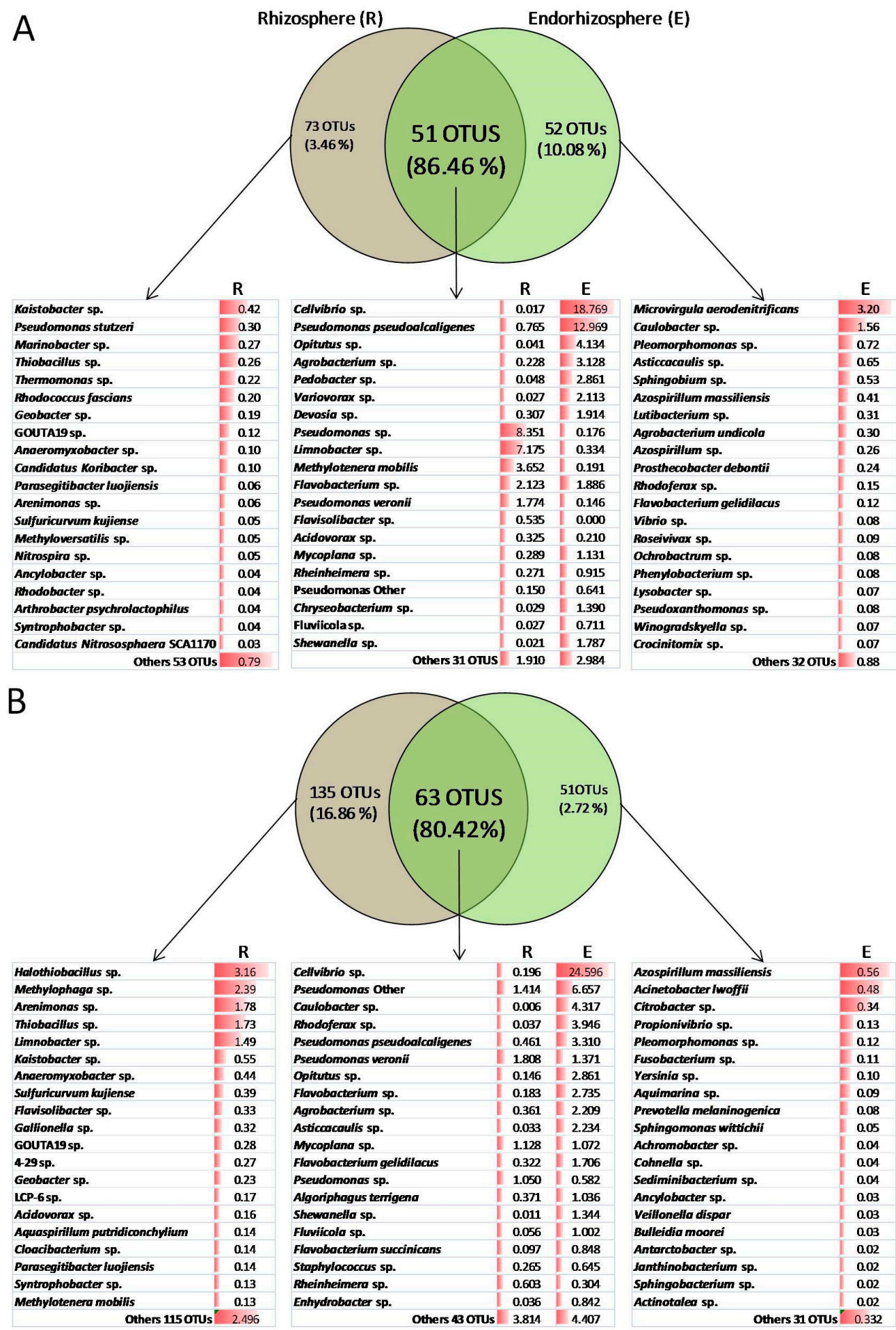

Figure 2. Microbiota composition of the two rice cultivars. A total of 383 OTUs were identified by $16 \mathrm{~S}$ rRNA sequencing profiling, using a $97 \%$ of similarity against the database. 326426 reads were obtained, 256701 from Pionero 2010 FL (A) and 69795 from DANAC SD20A (B) cultivar. The values in the Venn diagrams indicate the number of OTUs found exclusively in the rhizosphere (R), endosphere (E) or those found in both compartments, and the number in parenthesis indicates the relative abundance of those OTUs. The 20 most abundant species detected in each compartment and their frequency are shown (\%). The length of the color bars represents the value in the cell. 
10 of 25

\subsection{Isolation of culturable bacteria from rhizosphere and endorhizosphere}

The adherent soil of 5 grams of roots (i.e. the rhizospheric soil) were serially diluted and plated by triplicate on $\mathrm{LB} / \mathrm{cycloheximidine} \mathrm{plates.} \mathrm{The} \mathrm{estimated} \mathrm{average} \mathrm{number} \mathrm{of} \mathrm{culturable} \mathrm{bacteria}$ recovered was $5.5 \times 10^{7} \mathrm{CFU}$ per gram of rhizospheric soil. On the other hand, the 5 grams of roots yielded from 1420 to 361120 , with an average of 121076 CFU per gram of sterilized-macerated roots. In order to perform the plant-growth promoting tests, 87 putative endophytic bacterial isolates were chosen based on color and colony morphology differences.

\subsection{Production of indoleacetic acid (IAA)}

It was decided to test the 87 putative bacterial endophytic isolates for the production of IAA, the main auxin in plants and an important phenotype linked to plant growth promotion. Thirty-five of the isolates were positive to IAA production, 17 from Pionero $2010 \mathrm{FL}$ and 18 isolates from DANAC SD20A. The IAA production ranged from 0.153 to $4.860 \mu \mathrm{g} / \mathrm{mg}^{-1}$ and 15 representative isolates (Figure 3) were chosen for further characterization, namely: E1101, E1103, E1108, E1201, E1205, E1308, E2102, E2105, E2202, E2205, E2309, E2315, E2321, E2330 and E2330.

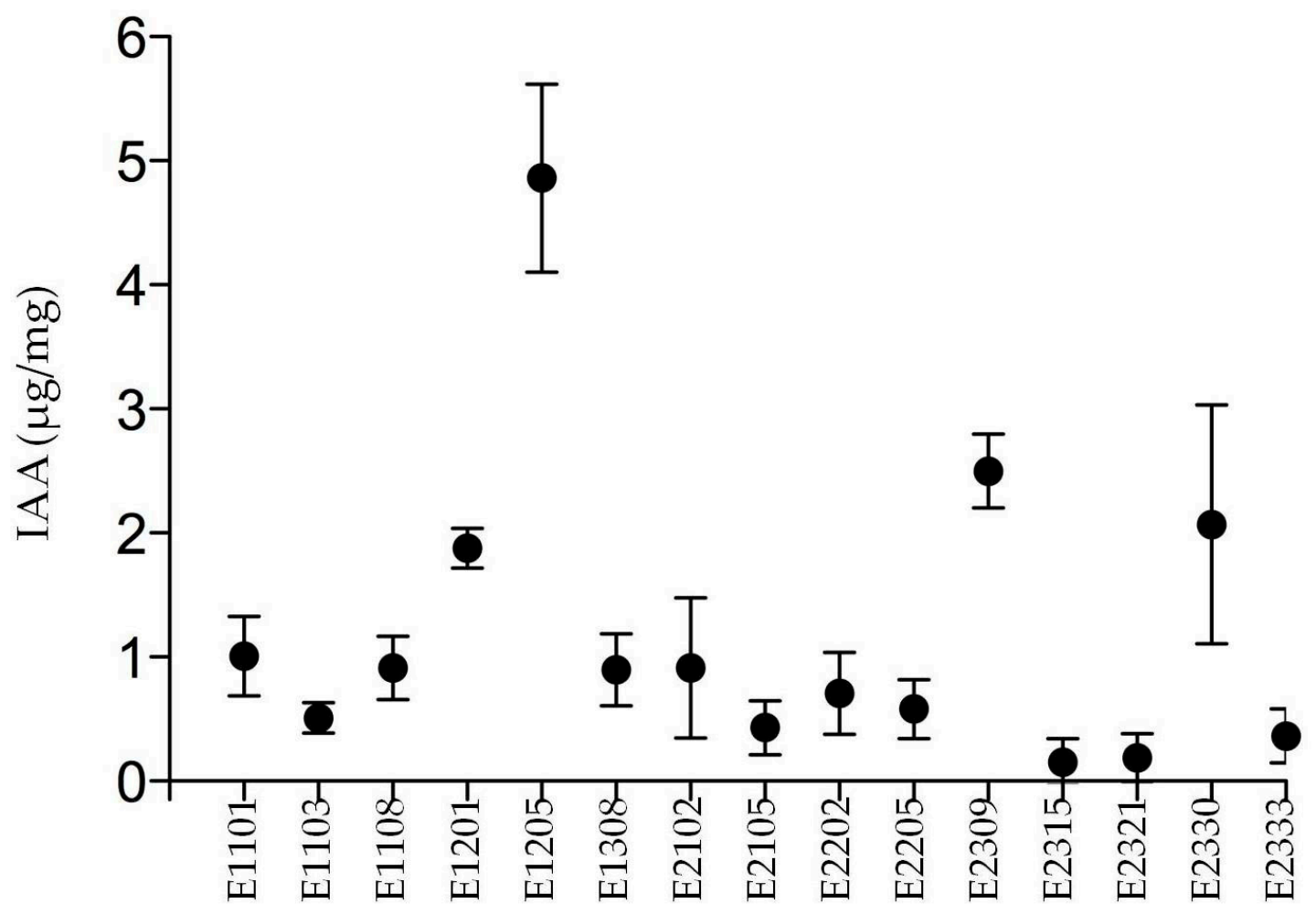

Figure 3. Production of indole acetic acid (IAA) by the putative endophyte isolates. Supernatants of each bacterial culture was spectrophotometrically analyzed after the Salvkoski reaction for the presence of IAA and the parallel construction of a calibration curve. Each dot represents the average reading of three biological replicates and the vertical bars is the standard deviation. The values correspond to micrograms of IAA per milligram of dry bacterial biomass. 
11 of 25

\subsection{Molecular identification}

In order to identify and classify the 15 bacterial isolates which produced IAA, they were subjected to $16 \mathrm{~S}$ rDNA amplification and sequencing. The sequence comparison against the ribosomal database revealed that 2 isolates belong to the Firmicutes phylum (E1101, Bacillus amyloliquefaciens and E2315 as B. pumilus) and 13 to Proteobacteria. Of these, 1 belongs to $\alpha$-Proteobacteria (E2321, Agrobacterium sp.), 1 to $\beta$-Proteobacteria (E2330, Delftia tsuruhatensis) and 11 to Y-Proteobacteria (E2105 and E2309, Serratia fonticola; E2102, Aeromonas diversa; E2202, A. hydrophila; E2205, A. veronii; E1201, Pseudomonas sp.; E1103, P. aeruginosa; E1108, P. mendocina; E1205, P. pseudoalcaligenes; E1308, P. fluorecens; E2333, P. jessenii). The $16 \mathrm{~S}$ sequences were used for determining the phylogenetic relationships through a cladogram as shown in Figure $4 \mathrm{~A}$.

A

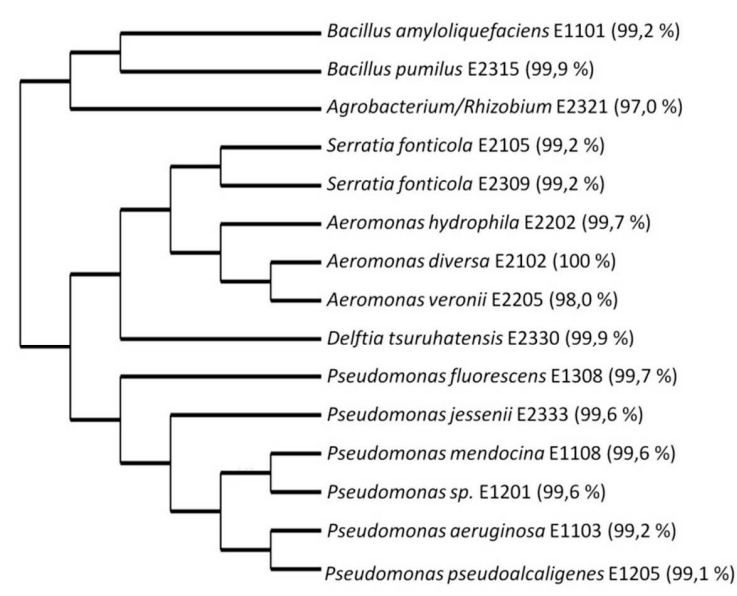

B

\begin{tabular}{|c|c|c|c|c|c|c|c|c|c|c|c|c|c|c|}
\hline 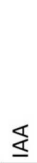 & $\stackrel{N}{z}$ & a & 己ِّ & 至 & ơ & $\underset{\mathrm{Z}}{\mathrm{u}}$ & 气 & $\frac{\xi}{\xi}$ & $\begin{array}{l}E \\
\frac{E}{N 0} \\
\sum_{n}^{\pi}\end{array}$ & 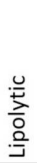 & 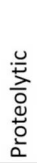 & 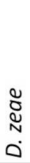 & 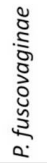 & 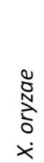 \\
\hline+ & + & - & - & - & - & $\cdot$ & - & + & + & + & + & + & + & + \\
\hline+ & + & + & - & - & - & - & + & + & + & - & + & - & - & nd \\
\hline+ & + & - & + & - & - & - & + & + & + & - & - & - & - & nd \\
\hline+ & - & + & - & - & + & - & - & - & - & - & - & - & - & nd \\
\hline+ & - & - & + & - & + & - & - & + & + & - & - & - & - & nd \\
\hline+ & - & + & - & + & - & - & - & + & + & + & + & - & - & nd \\
\hline+ & - & + & - & + & - & - & - & + & + & + & + & - & - & nd \\
\hline+ & - & + & - & + & - & - & - & + & + & + & + & - & - & nd \\
\hline+ & - & - & - & - & + & - & - & + & + & + & + & - & + & nd \\
\hline+ & + & + & - & - & - & - & - & + & - & + & - & - & + & + \\
\hline+ & + & + & - & - & - & + & + & + & - & - & - & - & + & - \\
\hline+ & - & - & - & - & + & - & - & + & - & + & - & - & - & + \\
\hline+ & - & - & - & - & + & - & - & + & + & + & - & - & - & + \\
\hline+ & - & - & - & - & + & - & - & + & - & + & - & - & - & + \\
\hline+ & - & - & - & - & - & - & - & + & - & - & - & - & - & + \\
\hline
\end{tabular}

Figure 4. Putative endophytic bacteria isolated from surface-sterilized rice roots. A) The bacterial isolates were putatively identified by $16 \mathrm{~S}$ sequencing and the rDNA sequences (average length 1518 $\mathrm{bp)}$ were used for constructing the cladogram. The homology percentages are shown in parenthesis. B) Plant-growth promoting activities and antibacterial activities detected in in vitro tests (IAA, indole acetic acid production; $\mathrm{N} 2$, nitrogen fixation; $\mathrm{P}$, phosphorous solubilization; ACCD, ACC deaminase activity; $\mathrm{AHL}$, acyl homoserine lactone production; $\mathrm{QQ}$, quorum quencher activity.; $\mathrm{HCN}$, hydrogen cyanide production; EPS, exopolysaccharide production; Swim and swarming and motility; Lipolytic and proteolytic activity; antibacterial activity against Dickeya zea, Pseudomonas fuscovaginae and Xanthomonas oryzae. The assays were performed in biological triplicates.

\section{4 in vitro assays of plant beneficial traits}

It was of interest to determine whether the 15 IAA producing putative rice bacterial endophytes possessed other important plant beneficial traits such as nitrogen fixation, phosphate solubilization, ACC deaminase activity, HCN production and antibacterial activities. Other relevant traits for endophytic life style like quorum sensing acyl-homoserine lactone (AHL) production, quorum quenching activity, exopolysaccharide (EPS) production, motility and secretion of enzymes were 
also assayed. The results of these assays are summarized in Figure 4B. Four isolates were positive to nitrogen fixation (E1101, E1308, E2315 and E2321), 7 to phosphate solubilization (E1308, E2102, E2105, E2202, E2205, E2315 and E2330), 2 to ACC deaminase (E2309 and E2321), 3 to AHL production (E2102, E2202 and E2205), 6 had quorum quenching activity (E2105, E2309, E2330, E1108, E1201 and E1103), 1 to HCN production (E2333), 3 to EPS production (E2315, E2321 and E2333), 14 showed swimming (all except E2105) and 9 had swarming activities (E1101, E1201, E2102, E2202, E2205, , E2309, E2315, E2321 and E2330). Secretion of enzymes was detected in 9 isolates for lipolytic activity (E1101, E1103, E1108, E1201, E1308 E2102, E2202, E2205 and E2330) and 6 to proteolytic activity (E1101, E2102, E2202, E2205, E2315 and E2330). Antibacterial activities towards three pathogens were determined and only 1 isolate showed antibacterial activity against Dickeya zea (E1101), 4 against Pseudomonas fuscovaginae (E1101, E1308, E2330, and E2333) and 6 against Xanthomonas oryzae (E1101, E1103, E1108, E1201, E1205 and E1308).

\subsection{Germination test, endophytism assay and plant-growth promotion}

The 15 isolates were in planta assayed for germination, endophytic colonization and plant growth promotion. For these experiments we created spontaneous rifampicin resistant mutant derivatives in order to select them after their recovery from colonized plant tissues. Only 2 strains significantly increased the germination rate of the seeds; Agrobacterium sp. E2315-germinated seeds were $7.6 \%$ higher in average than control seeds, and Serratia fonticola E2309 with a $7.3 \%$ germination increase (Figure 5A).

Of the 15 isolates tested, only 1 could be recovered after inoculation from the endorhizosphere, this was Pseudomonas fluorescens E1308. The CFU of this strain ranged from 170 to $44000 \mathrm{CFU} / \mathrm{g}^{-1}$. This isolate was also the best promoter of plant growth since the plants displayed an increase of $110 \%$ of the dry weight when compared to the control plants $(\mathrm{p}<0.05)$ (Figure 5B). Also other 8 strains showed a statistically significantly positive effect on plant growth promotion, namely $P$. mendocina E1108 (103 \%), Rhizobium sp. E2315 (103\%), Serratia fonticola E2105 (79 \%), P. jessenii E2333 (67 \%), Delftia tsuruhatensis E2330 (65 \%), Bacillus amyloliquefaciens E1101 (59 \%), P. pseudoalcaligenes E1205 (37 $\%)$ and Pseudomonas sp. E1201 (37\%); it is most likely that this promotion is linked to rhizosphere colonization. 
A

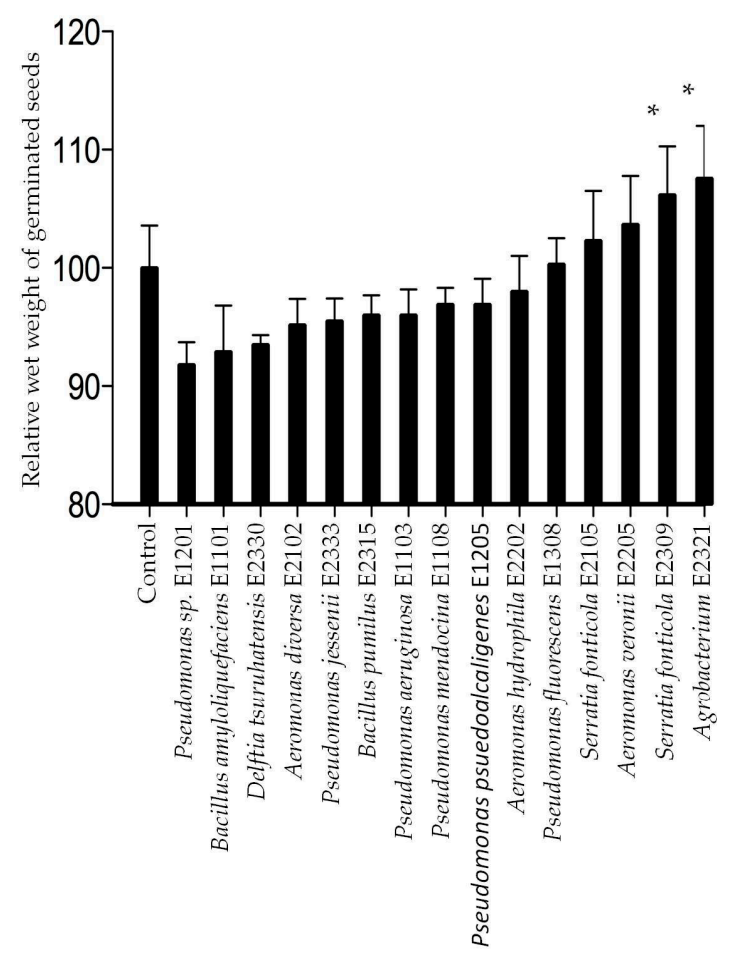

B

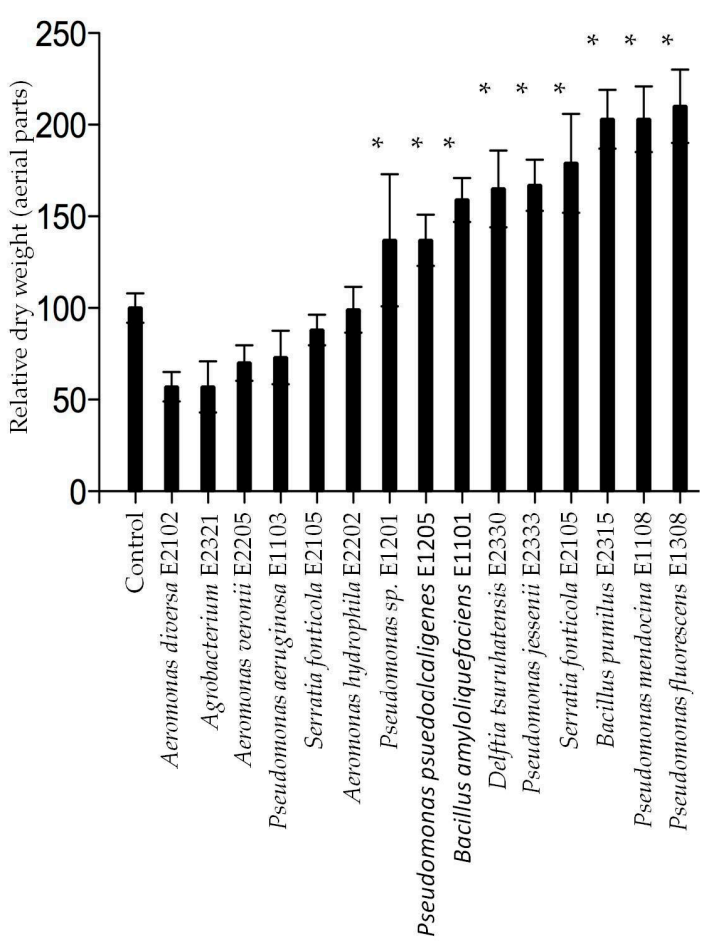

Figure 5. Plant growth promotion by single-strain inoculation. A) Germination rate. Results for each strain is shown as dispersion graph with the average and standard deviation as a red lines. B) Plant growing rate. The dry weight of the aerial parts (stems and leaves) was determined. The averages are shown relative to the control (arbitrarily 100) with its standard deviation. The values were obtained from 5 different inoculated plants cultivated during 15 days. The asterisks indicate statistical significance $(\mathrm{p}<0.05)$.

\subsection{Simplified community inoculation, colonization and plant growth promotion}

It was of interest to perform in planta studies with a bacterial consortium in order to determine possible bacterial inter-species community effects. It was decided to use a bacterial consortium 10 out of the 15 bacterial isolates, namely: P. mendocina E1108, P. pseudoalcaligenes E1205, P. fluorescens E1308, A. diversa E2102, A. veronii E2205, S. fonticola E2309, B. pumillus E2315, Rhizobium sp. E2321, D. tsuruhatensis E2330 and P. jessenii E2333. There was a significantly increase of $15 \%(p<0.05)$ in the wet weight of the inoculated plants compared to control non-inoculated, both in the roots and in aerial parts, after 30 days of gnotobiotic cultivation (Figure 6). 
14 of 25

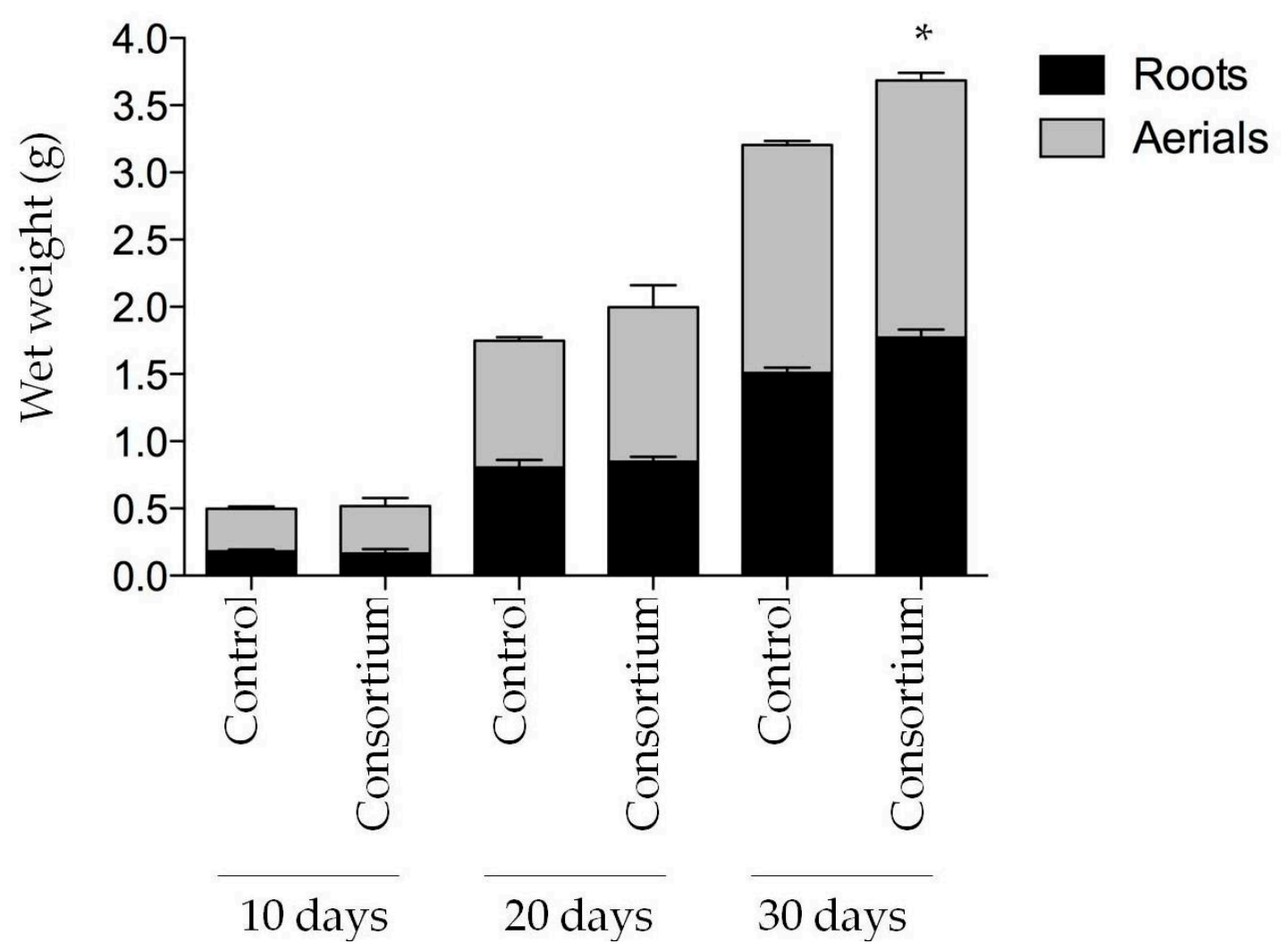

Figure 6. Effect of the bacterial consortium in plant growth. One-week old rice seedlings were inoculated with a mixture of 10 bacterial strains (A. diversa, A. veronii, Agrobacterium, Bacillus pumilus, Delftia tsuruhatensis, P. fluorescens, P. jessenii, P. mendocina and P. pseudoalcaligenes) and grown in controlled conditions for 10, 20 and 30 days. At each time point, 3 plants were harvested, cut in the two parts shown, and weighed. A control without bacterial inoculation was included. The asterisk indicates statistic significance $(\mathrm{p}<0.05)$.

An independent-culture approach was carried out to obtain insight into the colonization ability of the 10-strain simplified community inoculated as well as into its population abundances over time. The number of bacterial reads in the control non-inoculated plants was 83249 (46.9\%) at 10 days, $5118(4.4 \%)$ at 20 days and $2490(1.6 \%)$ at 30 days of growth. For the inoculated plants were 150609 $(97.7 \%), 73956$ (42.5\%) and 28655 (8.7\%) at each time point respectively (Figure 7A). The rest of the reads corresponded to plant DNA either plastidial and mithocondrial. Regarding to the total bacterial abundance, it was noted that the uninoculated plants were systematically lower in bacterial populations at each time point compared to that in inoculated plants; at 10 days they were $56872 \mathrm{vs}$ $150618(2.65 \mathrm{X})$, at 20 days 5081 vs.73956 (14.56 X) and at 30 days 2478 vs. 28531 (11.51 X) of total bacterial reads (Figure 7B). 
A

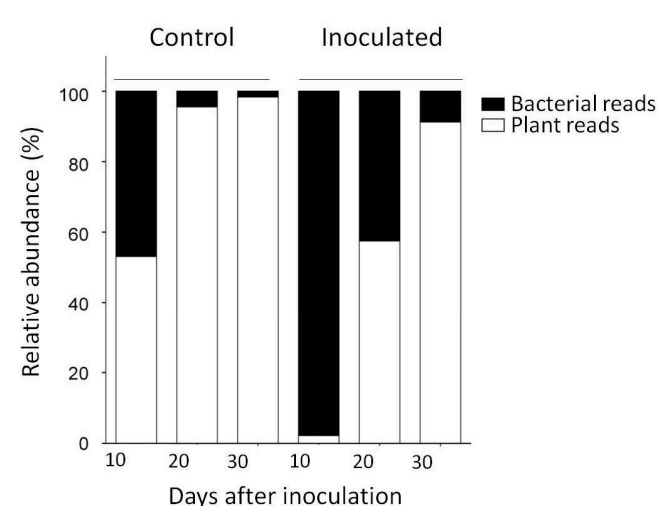

B

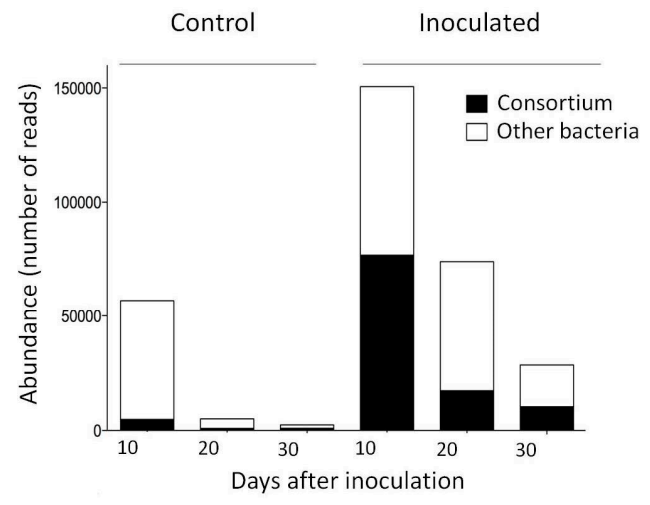

Figure 7. 16S library sequencing in the consortium inoculation. A) Ratio of plant vs. bacterial OTUs. The percentages of rice and bacterial 16S rRNA of each group of samples is plotted. The total numbers of reads were for control plants 10 days $n=177505 ; 20$ days $n=116321 ; 30$ days $n=155680$. For inoculated plants 10 days $n=154155 ; 20$ days $n=174015 ; 30$ days $n=329368$ reads. Control plants refer to un-inoculated plants. B) Distribution of the bacterial reads within the samples. The total bacterial reads is plotted for every group of samples and differentiated among those sequences matching with the 10 strains used in the inoculum (consortium) and those with no match with the consortium (other bacteria).

The composition of the initial inoculum (the pooled bacterial cultures that was then used as inoculum) varied from 36 reads (P. mendocina E1108) to 13145 reads (S. fonticola E2309) in a total of 45246 reads, as shown in Figure 8A. In order to track the abundance of each strain of the bacterial consortium within the plants, their $16 \mathrm{~S}$ sequences were used against the total $16 \mathrm{~S}$ rDNA library sequenced. This was also performed for the control plants in order to determine if any seed borne bacterial endophyte was taxonomically close enough to the strains used in the consortium, which could lead to false positives. The abundance of the simplified bacterial community was tracked in control and inoculated plants and it is represented as relative abundances in Figure 8B.

A

B
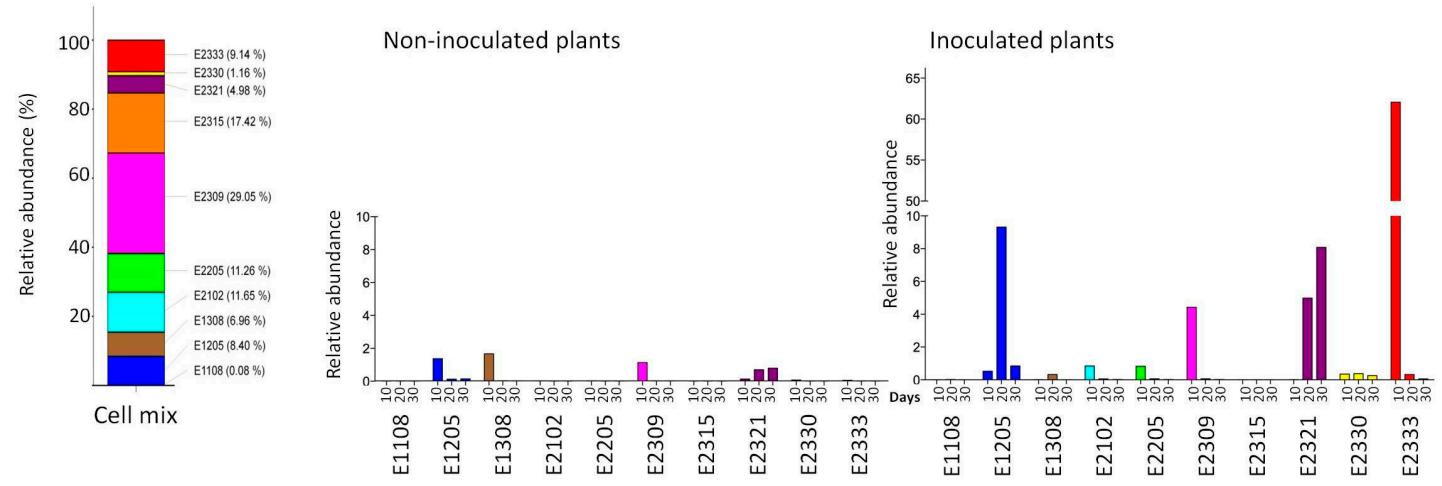

Figure 8. Composition of the 10-strains simplified community and its abundance during $\mathbf{3 0}$ days growth of rice seedlings. A) The cell mix represents the 10 species mixed and used as inoculum. The relative abundance of each strain is shown in brackets. The total number of reads was $n=45246$. B) 
16 of 25

The relative abundance of each consortium strain was tracked at 10, 20 and 30 days after the inoculation of the rice seedlings. The results for non-inoculated and inoculated plants are shown in the colored bars. The total number of reads was $n=111291$.

The abundance and identity of the reads suggested that taxonomically related strains to $P$. pseudoalcaligenes E1205, P. fluorescens E1308, S. fonticola E2309 and Agrobacterium sp. E2321 were present in the control plants in low abundance. In the inoculated plants, at least 8/10 bacterial strains were detected within the plant roots. Only 4 strains were however detected after 30 days of cultivation, namely: P. pseudoalcaligenes E1205, Agrobacterium sp. E2321, D. tsuruhatensis E2330 and P. jessenii E2333. This data set suggested that these strains were capable to colonize together the rice root and Table 2 summarizes the bacterial abundances detected in this experiment.

Table 2. Tracking of each bacterial strain in the consortium inoculation. The relative abundance of each strain is shown as detected in every time point (10, 20 and 30 days after inoculation) in control and inoculated plants. The total number of reads was $\mathrm{n}=111291$.

Control plants

Inoculated plants

\begin{tabular}{|c|c|c|c|c|c|c|}
\hline & 10 & 20 & 30 & 10 & 20 & 30 \\
\hline $\begin{array}{r}\text { E1108 } \\
\text { P. mendocina }\end{array}$ & 0 & 0 & 0 & 0.004 & 0.018 & 0.003 \\
\hline $\begin{array}{r}\text { E1205 } \\
\text { P. pseudoalcaligenes }\end{array}$ & 1.353 & 0.108 & 0.124 & 0.527 & 9.319 & 0.846 \\
\hline $\begin{array}{r}\text { E1308 } \\
\text { P. fluorescens }\end{array}$ & 1.656 & 0.015 & 0.004 & 0.016 & 0.326 & 0.005 \\
\hline $\begin{array}{r}\text { E2102 } \\
\text { A. diversa }\end{array}$ & 0.011 & 0 & 0 & 0.847 & 0.058 & 0.026 \\
\hline $\begin{array}{r}\text { E2205 } \\
\text { A. veronii }\end{array}$ & 0.011 & 0 & 0 & 0.827 & 0.061 & 0.018 \\
\hline $\begin{array}{r}\text { E2309 } \\
\text { S. fonticola }\end{array}$ & 1.116 & 0 & 0.002 & 4.433 & 0.068 & 0.022 \\
\hline $\begin{array}{r}\text { E2315 } \\
\text { B. pumilus }\end{array}$ & 0 & 0 & 0 & 0 & 0.002 & 0 \\
\hline $\begin{array}{r}\text { E2321 } \\
\text { Agrobacterium sp. }\end{array}$ & 0.122 & 0.685 & 0.778 & 0 & 4.979 & 8.077 \\
\hline $\begin{array}{r}\text { E2330 } \\
\text { D. tsuruhatensis }\end{array}$ & 0.066 & 0 & 0.007 & 0.340 & 0.366 & 0.251 \\
\hline $\begin{array}{r}\text { E2333 } \\
\text { P. jessenii }\end{array}$ & 0.047 & 0.004 & 0 & 62.062 & 0.330 & 0.058 \\
\hline
\end{tabular}


17 of 25

\section{Discussion}

It is of great importance to study the microbiota diversity and functionality on the main agricultural crops [18], as well as to develop models for the study of plant-microbes interaction through simplified microbiota [36]. In this study, (i) we have performed a survey on non-cultivable bacterial endophytic community in Oryza sativa cv. Pionero FL 2010 and O. sativa cv. DANAC SD20A, (ii) we have carried out the isolation and partial characterization of 15 putative bacterial endophytes, and (iii) we have narrowed a 4-strains simplified microbiota is a starting point for a working model for bacteria-bacteria and bacteria-plant interactions in rice.

\subsection{Amplicon-based taxonomic profiling.}

Profiling the bacterial communities allowed us to determine that the rhizospheres of both rice cultivars were more diverse than the endorhizospheres, an observation widely documented [37], [38]. Proteobacteria were by far the most predominant group in both compartments of both rice varieties, and this is in agreement with several previous studies [14][15][39]. However, members of Deltaproteobacteria and Epsilonproteobacteria class were not detected in the endorhizospheres analyzed here; this is in contrast to what has been reported in a previous report of rice microbiome in Italy [15]. The abundance of Delta and Epsilonproteobacteria in the study in rice in Italy totaled 5.4 and $4.9 \%$ of the total endophytic population, respectively, while in the IR55423-01 rice from the Philippines analyzed by [14] they represented 2.6 and the $0.5 \%$ of the total bacterial population respectively.

We further compared the OTUs abundance differentially distributed between the rhizosphere and the endorhizosphere of each rice cultivar. We identified members of Cellvibrio genus as being highly predominant inhabitants in both endorhizospheres. The members of this genus are known as obligates aerobic cellulolytic bacteria and other complex carbohydrates degraders [40] which are believed to be key activities necessary for the colonization of the plant endosphere. Cellvibrio spp. have been reported as members of the rice endosphere [15], however with a lower abundance (between 0.01 and $<1 \%$ ). In addition Cellvibrio species are nitrogen fixing bacteria, especially the Cellvibrio diazotrophicus [41]. C. diazotrophicus has been reported as an enriched endophyte in Medicago truncatula when subjected to salinity stress [42], and also has been found in the endosphere of cannabis, potato and banana [43]-[45]. Other species enriched in both endospheres were $P$. pseudoalcaligenes, Agrobacterium sp. and Opitutus sp. Endophytic P. pseudoalcaligenes and Agrobacterium sp. have been previously reported in rice [46], [47] and they have also been frequently isolated from different plant types and tissues [48]-[51]. Opitutus sp. has been reported as an inhabitant of anoxic rice paddy soils [52] and as a rice endophyte [15], moreover members of Verrucomicrobiae in the rice endosphere have also been reported by [14]. Interesting Opitutus sp. is obligate anaerobic with fermentative metabolism that utilizes rice plant-derived carbons [37]. The presence of anaerobic microbes within the plant, an environment which is $\mathrm{O}_{2}$-rich, seems paradoxical and was also reported by [39].

In the Pionero FL 2010 cultivar, Pedobacter, Variovorax and Devosia genus were enriched in the endorhizosphere with respect to the rhizosphere. Pedobacter sp. has been isolated from rice paddy soil [53], from the endorhizosphres of maize [54], potato [55] and raygrass [56]. Variovorax sp. is a 
versatile PGP bacterium able to colonize the plant endosphere [57] including rice [58]. Devosia sp. is a soil bacterium from the Rhizobiales family, nodule forming and nitrogen fixing [59] and has also been reported in the potato endorhizosphere [55]. Bacteria belonging to these three genera have been detected in the rice endosphere of rice grown in Italy [15].

Two bacterial species counted for half of the total bacterial population in the endosphere of Pionero FL 2010. First, Microvirgula aerodenitrificans, the most abundant one, is an aerobic denitrifier [60] and has been reported previously as a rice endorhizosphere inhabitant [15]. Secondly Caulobacter sp., which has also been reported to be associated rice in two other parts of the world [61][62][15] and to have PGP properties [48]. In the endorhizosphere of the DANAC SD20A rice cultivar, strains belonging to the Azospirillum, Acinetobacter and Citrobacter genera were dominant. Azospirillum and Acinetobacter are diazotrophic plant-growth promoting bacteria that can modulate the phytohormone balance [63][64]. To our knowledge, there is just one report of the isolation of Citrobacter as rice endophyte [65], although the rice metagneomic study most likely revealed loci which belong to Citrobacter sp. [14]. Apart from Cellvibrio, P. pseudoalcaligenes and Opitupus sp., the endosphere of the DANAC SDS20A cultivar was highly enriched by Rhodoferax sp., a nitrate reducer bacterium [66].

Both rhizospheres were enriched of denitrifying, iron-reducing, sulfur/sulfate-reducing, heavy-metal tolerant, halotolerants, methylotrophs, thisulfate-oxidizing and polycyclic aromatic hydrocarbons degrader species, a microbiota quiet different to that found in the inner tissue of the rice roots. This data therefore strengthens the concept of the niche-mediated plant microbiota structure [67].

It is important to mention that this analysis is subjected to intrinsic bias of the amplification and sequencing techniques, as well as the data processing [18]; thus some taxa could not be appropriately represented in our study. Nevertheless, the taxonomic range of putative endophytic microbiota of rice has been extended with this work, making an important contribution to the rice microbiome research, improving the progress towards the elucidation of the rice core microbiota.

\subsection{Isolation of putative endophytic bacteria, determination of its PGP traits and plant colonization.}

Beneficial endophytic bacteria play important roles that positively affect directly or indirectly plant growth and development [19]. In this study we selected 15 putative bacterial endophytes isolated from Venezuelan rice because they were IAA producers. IAA is the main auxin in plants, controlling the roots architecture, thereby improving nutrient acquisition [68]-[70]. Our estimations of the produced IAA are related to milligrams of dry bacterial biomass since we think it could be more informative for future comparisons.

Two Bacillus strains (Firmicutes phylum), B amyloliquefaciens E1101 and B. pumilus E2315, were identified among our isolates. Although these two strains did not affect the germination rate of the surface-sterilized rice seeds, they positively influenced the plant growth however our inoculation experiments did not reveal them as endophytes. Bacillus spp. are widely used commercially as biofertilizer and biocontrol agents in agriculture due to their spore forming ability and stability in 
their formulations. Particulary, B. amyloliquefaciens has shown the most potent antibacterial activity, antagonizing or inhibiting growth of 14 bacterial species (data not shown). B. amyloliquefaciens is known to produce surfactins and an array of secondary metabolites and is considered a model for unraveling plant-microbe interactions and biocontrol [71]. It is interesting to note that in our taxonomic profiling, Bacilli abundance was extremely low in the four compartments analyzed, with a maximum abundance of $0.016 \%$ of the total reads. The rest of our 13 isolates belong to Proteobacteria, the most abundant phylum in the taxonomic analysis. The alfaproteobacteria Agrobacterium sp. E2321 had the most positive impact on the germination rate, but this did not translate in a plant growth promotion. This strain displayed a number of PGP traits in vitro however was not able perform beneficial effects in planta; this contradiction was discussed by [72] when they found similar discordance when analyzed the effect of rhizobacteria on the growth of barley under salt stress. These results suggest that the current in vitro PGP screening methods may need to be re-evaluated. The isolate Serratia fontica E2309 was the only bacterial inoculum that increased the germination rate and also plant growth. Others Serratia spp. have been previously reported as PGP strains [73]-[75] and could therefore be a good candidate to further study. The S. fonticola isolate (isolate E2105), however did not promote the plant growth. Interestingly our two S. fonticola isolates displayed a different profile of in vitro activities thus despite being to the same species, there are probable differences between the two isolates which affect the PGP performance.

Other isolates such as D. tsuruhatensis E2330 and Pseudomonas spp. did not affect the germination rate but promoted the plant growth. $D$. tsruhatensis was isolated and described for the first time from a water treatment plant in Japan [76] later also from the rhizosphere of rice and considered as a PGP bacterium [77]. D. tsuruhatensis E2330 showed the strongest quorum quenching activity in vitro. Delftia sp. VM4 was reported to possess AHL-acylase activity [78], we speculate that our isolate could also posses this enzyme activity as quorum sensing interference. Pseudomonas spp., are very abundant members of the rice endorhizospheres [14][62][79][80], however only P. aeruginosa E1103 displayed some PGP activity in the conditions that we tested. The Aeromonas spp. isolates did not show PGP activity or improved germination; Aeromonas isolates have however been reported to have PGP activity in tomato [81] and rice [82][83].

Of the 15 isolates re-inoculated, only P. fluorescens E1308 could be re-isolated from the endopshere; we cannot exclude possible limitations of our methods/analysis. For instance, endophytic strains were isolated from two rice cultivars genotypically different from the one used in the in planta experiments hence it is possible that plant genotype influences endopshere colonization/microbiota [36], [84]-[86].

\subsection{Seedling inoculation with a simplified bacterial community.}

Microorganisms do not act as individuals but rather act as a dynamically changing microbial community, where cells interact and communicate with one another. This communication influences bacterial behavior significantly affecting the phenotypes of the microbial community [87]. It is therefore of importance to develop new model systems for incorporating communities of microorganisms in plant microbiota research [36]. The use of traceable simplified ecosystems reduces the complexity of naturally complex microbiota and its investigation increase our 
knowledge regarding factors that shape and influence microbial communities. We therefore performed rice inoculations with a 10 strain simplified community in order to assess its potential for host colonization and possible differences compared to single strain inoculations. We did not use strains which possessed strong in vitro antibacterial activity. Assessing colonization via 16S rDNA gene community profiling showed that 8 strains were detected in the endorhizosphere. Within this group, P. pseudoalcaligenes E1205, Agrobacterium sp. E2321, D. tsuruhatensis E2330 and P. jessenii E2333 remained as endorhizosphere inhabitants after 30 days of plant growth. The isolate $P$. fluorescens E1308, the only one recovered from surface-sterilized inoculated rice plants in the single-strain in planta tests, was surprisingly not detected when co-inoculated with 9 other strains. The bacterial community can be influencing the endophytic colonization of this strain or the host plant favored the colonization of other strains. The design of simplified microbial communities has been recently considered as a priority for harnessing the plant microbiome in sustainable agriculture [36] and this approach has been addressed in Arabidopsis [88] and in maize [67]. In this work we initiated PGP and colonization studies of a simplified community of 10 bacterial strains and initial results encourage further studies of synergistic, signaling and cooperative behavior of a multispecies consortium as well as the role of the plant genotype.

Acknowledgments: We wish to thank Dr. Alejandro Pieters from the IVIC for logistic support and to Dr. Rosa Alvarez from the Instituto de Investigaciones Agricolas - Portuguesa, Venezuela, for the support during sampling. The graphic abstract icons were obtained from Noun Project (htt://thenounproject.com). FMB is the recipient of an ICGEB Arturo Falaschi fellowship.

Author Contributions: F.MB. and V.V. conceived and designed the experiments and wrote the paper; F.MB. performed the experiments; F.G. performed the 16S rRNA library construction and sequencing and A.P. analyzed the data. E.M. provided logistical and negotiation support for the undertaking of this binational work.

Conflicts of Interest: The authors declare no conflict of interest.

\section{References}

[1] Food and Agriculture Organization of the United Nations, "FAO Statistical Yearbook 2013: World food and agriculture," FAO Stat. Yearb. 2013 World food Agric., pp. 1-307, 2013.

[2] U. A. Naher, R. Othman, Q. A. Panhwar, and M. R. Ismail, “Biofertilizer for sustainable rice production and reduction of environmental pollution," in Crop Production and Global Environmental Issues, 2015.

[3] J. S. Singh, V. C. Pandey, and D. P. Singh, “Efficient soil microorganisms: A new dimension for sustainable agriculture and environmental development," Agriculture, Ecosystems and Environment, vol. 140, no. 3-4. 2011.

[4] Y. C. Kim, J. Leveau, B. B. McSpadden Gardener, E. A. Pierson, L. S. Pierson, and C. M. Ryu, “The multifactorial basis for plant health promotion by plant-associated bacteria," Applied and Environmental Microbiology, vol. 77, no. 5. pp. 1548-1555, 2011.

[5] C. M. J. Pieterse, C. Zamioudis, R. L. Berendsen, D. M. Weller, S. C. M. van Wees, and P. a H. M. Bakker, "Induced Systemic Resistance by Beneficial Microbes.," Annu. Rev. Phytopathol., no. May, pp. $1-29,2014$.

[6] J. Vacheron et al., "Plant growth-promoting rhizobacteria and root system functioning.," Front. Plant Sci., vol. 4, no. September, p. 356, 2013.

[7] B. Lugtenberg and F. Kamilova, "Plant-growth-promoting rhizobacteria.," Annu. Rev. Microbiol., vol. 63, pp. 541-556, 2009. 
[8] P. N. Bhattacharyya and D. K. Jha, "Plant growth-promoting rhizobacteria (PGPR): Emergence in agriculture," World Journal of Microbiology and Biotechnology, vol. 28, no. 4. pp. 1327-1350, 2012.

[9] M. Rosenblueth and E. Martínez-Romero, "Bacterial endophytes and their interactions with hosts.," Mol. Plant. Microbe. Interact., vol. 19, no. 8, pp. 827-837, 2006.

[10] D. N. Nair and S. Padmavathy, "Impact of endophytic microorganisms on plants, environment and humans," The Scientific World Journal, vol. 2014. 2014.

[11] B. Reinhold-Hurek and T. Hurek, “Living inside plants: Bacterial endophytes,” Current Opinion in Plant Biology, vol. 14, no. 4. pp. 435-443, 2011.

[12] G. Brader, S. Compant, B. Mitter, F. Trognitz, and A. Sessitsch, “Metabolic potential of endophytic bacteria," Current Opinion in Biotechnology, vol. 27. pp. 30-37, 2014.

[13] S. Marella, "Bacterial endophytes in sustainable crop production: applications, recent developments and challenges ahead," Int J Life Sci Res, vol. 2, pp. 46-56, 2014.

[14] A. Sessitsch et al., "Functional Characteristics of an Endophyte Community Colonizing Rice Roots as Revealed by Metagenomic Analysis," Molecular Plant-Microbe Interactions, vol. 25, no. 1. pp. 28-36, 2012.

[15] I. Bertani, P. Abbruscato, P. Piffanelli, S. Subramoni, and V. Venturi, “Rice bacterial endophytes: Isolation of a collection, identification of beneficial strains and microbiome analysis," Environ. Microbiol. Rep., 2016.

[16] P. R. Hardoim, F. D. Andreote, B. Reinhold-Hurek, A. Sessitsch, L. S. van Overbeek, and J. D. van Elsas, "Rice root-associated bacteria: Insights into community structures across10 cultivars," FEMS Microbiol. Ecol., vol. 77, no. 1, pp. 154-164, 2011.

[17] D. Bulgarelli, K. Schlaeppi, S. Spaepen, E. Ver Loren van Themaat, and P. Schulze-Lefert, "Structure and functions of the bacterial microbiota of plants.," Annu. Rev. Plant Biol., vol. 64, 2013.

[18] K. Schlaeppi and D. Bulgarelli, “The Plant Microbiome at Work," Mol. Plant-Microbe Interact. MPMI, vol. 212, no. 3, 2015.

[19] D. B. Müller, C. Vogel, Y. Bai, and J. A. Vorholt, “The Plant Microbiota: Systems-Level Insights and Perspectives," Annu. Rev. Genet., vol. 50, no. 1, 2016.

[20] J. G. Caporaso et al., “Global patterns of $16 \mathrm{~S}$ rRNA diversity at a depth of millions of sequences per sample," Proc. Natl. Acad. Sci., 2011.

[21] M. J. Claesson et al., “Comparative analysis of pyrosequencing and a phylogenetic microarray for exploring microbial community structures in the human distal intestine," PLoS One, 2009.

[22] B. E. Arenz, D. C. Schlatter, J. M. Bradeen, and L. L. Kinkel, “Blocking primers reduce co-amplification of plant DNA when studying bacterial endophyte communities," J. Microbiol. Methods, 2015.

[23] J. M. Bric, R. M. Bostock, and S. E. Silverstone, "Rapid in situ assay for indoleacetic acid production by bacteria immobilized on a nitrocellulose membrane," Appl. Environ. Microbiol., vol. 57, no. 2, pp. 535-538, 1991.

[24] R. Pikovskaya, "Mobilization of phosphorous in soil in connection with vital activity of some microbial species," Microbiologiya, vol. 17, pp. 362-370, 1948.

[25] D. M. Penrose and B. R. Glick, "Methods for isolating and characterizing ACC deaminase-containing plant growth-promoting rhizobacteria," Physiol Plant, vol. 118, no. 1, pp. 10-15, 2003.

[26] S. Mehnaz, D. N. Baig, and G. Lazarovits, “Genetic and Phenotypic Diversity of Plant Growth Promoting Rhizobacteria Isolated from Sugarcane Plants Growing in Pakistan," J. Microbiol. Biotechnol., vol. 20, no. 12, pp. 1614-1623, 2010.

[27] K. H. McClean et al., "Quorum sensing and Chromobacterium violaceum: Exploitation of violacein 
production and inhibition for the detection of N-acylhomoserine lactones," Microbiology, vol. 143, no. 12, pp. 3703-3711, 1997.

[28] T. Kohler, L. K. Curty, F. Barja, C. Van Delden, and J. C. Pechere, “Swarming of Pseudomonas aeruginosa is dependent on cell-to-cell signaling and requires flagella and pili," J. Bacteriol., 2000.

[29] J. E. A. Zlosnik, T. J. Hird, M. C. Fraenkel, L. M. Moreira, D. A. Henry, and D. P. Speert, “Differential mucoid exopolysaccharide production by members of the Burkholderia cepacia complex," J. Clin. Microbiol., 2008.

[30] M. S. Smeltzer, M. E. Hart, and J. J. Iandolo, “Quantitative spectrophotometric assay for staphylococcal lipase," Appl. Environ. Microbiol., 1992.

[31] B. Huber et al., "The cep quorum-sensing system of Burkholderia cepacia H111 controls biofilm formation and swarming motility," Microbiology, 2001.

[32] A. Dereeper et al., "Phylogeny.fr: robust phylogenetic analysis for the non-specialist.," Nucleic Acids Res., 2008.

[33] D. R. Hoagland and D. I. Arnon, The water-culture method for growing plants without soil. 1950.

[34] S. V Angiuoli et al., "CloVR: A virtual machine for automated and portable sequence analysis from the desktop using cloud computing," BMC Bioinformatics, 2011.

[35] J. G. Caporaso et al., “QIIME allows analysis of high-throughput community sequencing data.,” Nat. Methods, 2010.

[36] P. E. Busby et al., "Research priorities for harnessing plant microbiomes in sustainable agriculture," PLoS Biol., 2017.

[37] M. Hernández, M. G. Dumont, Q. Yuan, and R. Conrad, “Different bacterial populations associated with the roots and rhizosphere of rice incorporate plant-derived carbon," Appl. Environ. Microbiol., 2015.

[38] R. Mendes, P. Garbeva, and J. M. Raaijmakers, “The rhizosphere microbiome: Significance of plant beneficial, plant pathogenic, and human pathogenic microorganisms," FEMS Microbiology Reviews, vol. 37, no. 5. 2013.

[39] J. Edwards et al., "Structure, variation, and assembly of the root-associated microbiomes of rice.," Proc. Natl. Acad. Sci. U. S. A., vol. 112, no. 8, 2015.

[40] R. T. DeBoy et al., "Insights into plant cell wall degradation from the genome sequence of the soil bacterium Cellvibrio japonicus," J. Bacteriol., 2008.

[41] C. Suarez, S. Ratering, I. Kramer, and S. Schnell, “Cellvibrio diazotrophicus sp. nov., a nitrogen-fixing bacteria isolated from the rhizosphere of salt meadow plants and emended description of the genus Cellvibrio," Int. J. Syst. Evol. Microbiol., 2014.

[42] M. W. Yaish, A. Al-Lawati, G. A. Jana, H. V. Patankar, and B. R. Glick, "Impact of soil salinity on the structure of the bacterial endophytic community identified from the roots of caliph medic (Medicago truncatula)," PLoS One, 2016.

[43] M. E. Winston et al., "Understanding cultivar-specificity and soil determinants of the Cannabis microbiome," PLoS One, 2014.

[44] A. Sessitsch, B. Reiter, U. Pfeifer, and E. Wilhelm, “Cultivation-independent population analysis of bacterial endophytes in three potato varieties based on eubacterial and Actinomycetes-specific PCR of 16S rRNA genes," FEMS Microbiol. Ecol., 2002.

[45] Y. Liu, S. Zuo, L. Xu, Y. Zou, and W. Song, “Study on diversity of endophytic bacterial communities in seeds of hybrid maize and their parental lines," Arch. Microbiol., 2012. 
[46] Y. Jha and R. B. Subramanian, “Endophytic Pseudomonas pseudoalcaligenes shows better response against the Magnaporthe grisea than a rhizospheric Bacillus pumilus in Oryza sativa (Rice)," Arch. Phytopathol. Plant Prot., 2011.

[47] P. R. Hardoim, C. C. P. Hardoim, L. S. van Overbeek, and J. D. van Elsas, “Dynamics of seed-borne rice endophytes on early plant growth stages," PLoS One, 2012.

[48] G. Gupta, S. S. Parihar, N. K. Ahirwar, S. K. Snehi, and V. Singh, "Plant Growth Promoting Rhizobacteria (PGPR): Current and Future Prospects for Development of Sustainable Agriculture," J. Microb. Biochem. Technol., 2015.

[49] E. J. Ruby, “A Review: Bacterial Endophytes and their Bioprospecting,” J. Pharm. Res., vol. 4, pp. 795-799, 2011.

[50] J. Hallmann, A. Quadt-Hallmann, W. F. Mahaffee, and J. W. Kloepper, "Bacterial endophytes in agricultural crops," Canadian Journal of Microbiology, vol. 43, no. 10. pp. 895-914, 1997.

[51] G. Santoyo, G. Moreno-Hagelsieb, C. Orozco-Mosqueda Mdel, and B. R. Glick, “Plant growth-promoting bacterial endophytes," Microbiol Res, 2016.

[52] K. J. Chin, W. Liesack, and P. H. Janssen, “Opitutus terrae gen. nov., sp. nov., to accommodate novel strains of the division 'Verrucomicrobia' isolated from rice paddy soil," Int. J. Syst. Evol. Microbiol., 2001.

[53] Y. Jeon et al., "Pedobacter oryzae sp. nov., isolated from rice paddy soil," Int. J. Syst. Evol. Microbiol., 2009.

[54] J. L. Gao, P. Sun, X. J. Mao, Y. L. Du, B. Y. Liu, and J. G. Sun, “Pedobacter zeae sp. Nov., an endophytic bacterium isolated from maize root," Int. J. Syst. Evol. Microbiol., 2017.

[55] D. K. Manter, J. A. Delgado, D. G. Holm, and R. A. Stong, “Pyrosequencing reveals a highly diverse and cultivar-specific bacterial endophyte community in potato roots," Microb. Ecol., 2010.

[56] Y. Liang, Y.-G. Zhu, F. Smith, and H. Lambers, "Soil-plant interactions and sustainability of eco-agriculture in arid region: a crucially important topic to address," Plant Soil, vol. 326, pp. 1-2, 2010.

[57] J. I. Han et al., "Complete genome sequence of the metabolically versatile plant growth-promoting endophyte Variovorax paradoxus S110," J. Bacteriol., 2011.

[58] Y. Wang et al., "Improved plant growth and Zn accumulation in grains of rice (Oryza sativa L.) by inoculation of endophytic microbes isolated from a Zn hyperaccumulator, Sedum alfredii H.," J. Agric. Food Chem., 2014.

[59] R. Rivas et al., "A new species of Devosia that forms a unique nitrogen-fixing root-nodule symbiosis with the aquatic legume Neptunia natans (L.f.) Druce," Appl. Environ. Microbiol., 2002.

[60] D. Patureau et al., "Microvirgula aerodenitrificans gen. nov., sp. nov., a new gram-negative bacterium exhibiting co-respiration of oxygen and nitrogen oxides up to oxygen-saturated conditions.," Int. J. Syst. Bacteriol., 1998.

[61] H. Mano, F. Tanaka, C. Nakamura, H. Kaga, and H. Morisaki, “Culturable endophytic bacterial flora of the maturing leaves and roots of rice plants (Oryza sativa) cultivated in a paddy field," Microbes Environ., 2007.

[62] H. Kaga, H. Mano, F. Tanaka, A. Watanabe, S. Kaneko, and H. Morisaki, "Rice Seeds as Sources of Endophytic Bacteria," Microbes Environ., 2009.

[63] R. K. Sahoo, M. W. Ansari, M. Pradhan, T. K. Dangar, S. Mohanty, and N. Tuteja, "Phenotypic and molecular characterization of native Azospirillum strains from rice fields to improve crop productivity," Protoplasma, 2014. 
[64] B. Drogue et al., "Plant root transcriptome profiling reveals a strain-dependent response during Azospirillum-rice cooperation.," Front. Plant Sci., 2014.

[65] P. R. Hardoim, Bacterial Endophytes of Rice - Their Diversity, Characteristics and Perspectives. Groningen: University of Groningen, 2011.

[66] A. H. J. Klemme, “Nitrate reduction in a new strain of Rhodoferax fermentans," Arch Microbiol, vol. 3, no. 164, pp. 358-362, 1995.

[67] B. Niu, J. N. Paulson, X. Zheng, and R. Kolter, “Simplified and representative bacterial community of maize roots.," Proc. Natl. Acad. Sci. U. S. A., vol. 114, no. 12, pp. E2450-E2459, 2017.

[68] D. Duca, J. Lorv, C. L. Patten, D. Rose, and B. R. Glick, “Indole-3-acetic acid in plant-microbe interactions.," Antonie Van Leeuwenhoek, 2014.

[69] P. Sukumar, V. Legué, A. Vayssières, F. Martin, G. A. Tuskan, and U. C. Kalluri, “Involvement of auxin pathways in modulating root architecture during beneficial plant-microorganism interactions," Plant, Cell Environ., 2013.

[70] S. Spaepen, J. Vanderleyden, and R. Remans, “Indole-3-acetic acid in microbial and microorganism-plant signaling," FEMS Microbiology Reviews. 2007.

[71] S. P. Chowdhury, A. Hartmann, X. W. Gao, and R. Borriss, “Biocontrol mechanism by root-associated Bacillus amyloliquefaciens FZB42 - A review," Frontiers in Microbiology. 2015.

[72] M. Cardinale, S. Ratering, C. Suarez, A. M. Zapata Montoya, R. Geissler-Plaum, and S. Schnell, "Paradox of plant growth promotion potential of rhizobacteria and their actual promotion effect on growth of barley (Hordeum vulgare L.) under salt stress," Microbiol. Res., 2015.

[73] U. Chakraborty, B. N. Chakraborty, and a. P. Chakraborty, "Influence of Serratia marcescens TRS-1 on growth promotion and induction of resistance in Camellia sinensis against Fomes lamaoensis," J. Plant Interact., 2010.

[74] S. Neupane et al., "Complete genome sequence of the rapeseed plant-growth promoting Serratia plymuthica strain AS9," Stand. Genomic Sci., 2012.

[75] U. Devi et al., “Draft Genome Sequence of a Plant Growth-Promoting Rhizobacterium, Serratia fonticola Strain AU-P3(3).," Genome Announc., 2013.

[76] T. Shigematsu, K. Yumihara, Y. Ueda, M. Numaguchi, S. Morimura, and K. Kida, “Delftia tsuruhatensis sp. nov., a terephthalate-assimilating bacterium isolated from activated sludge," Int. J. Syst. Evol. Microbiol., 2003.

[77] J. Han et al., "Characterization of a novel plant growth-promoting bacteria strain Delftia tsuruhatensis HR4 both as a diazotroph and a potential biocontrol agent against various plant pathogens," Syst. Appl. Microbiol., 2005.

[78] V. B. Maisuria and A. S. Nerurkar, "Interference of quorum sensing by Delftia sp. VM4 depends on the activity of a novel n-acylhomoserine lactone-acylase," PLoS One, 2015.

[79] J. Prakamhang, K. Minamisawa, K. Teamtaisong, N. Boonkerd, and N. Teaumroong, “The communities of endophytic diazotrophic bacteria in cultivated rice (Oryza sativa L.)," Appl. Soil Ecol., vol. 42, no. 2, pp. 141-149, 2009.

[80] H. Mano and H. Morisaki, "Endophytic Bacteria in the Rice Plant," Microbes and Environments, vol. 23, no. 2. pp. 109-117, 2008.

[81] P. R. Vaikuntapu, S. Dutta, R. B. Samudrala, V. R. V. N. Rao, S. Kalam, and A. R. Podile, "Preferential Promotion of Lycopersicon esculentum (Tomato) Growth by Plant Growth Promoting Bacteria Associated with Tomato," Indian J. Microbiol., 2014. 
[82] A. Banik, S. K. Mukhopadhaya, and T. K. Dangar, “Characterization of N2-fixing plant growth promoting endophytic and epiphytic bacterial community of Indian cultivated and wild rice (Oryza spp.) genotypes," Planta, 2016.

[83] J. Garcia-Cristobal, A. Garcia-Villaraco, B. Ramos, J. Gutierrez-Ma??ero, and J. A. Lucas, “Priming of pathogenesis related-proteins and enzymes related to oxidative stress by plant growth promoting rhizobacteria on rice plants upon abiotic and biotic stress challenge," J. Plant Physiol., 2015.

[84] M. R. Wagner, D. S. Lundberg, T. G. del Rio, S. G. Tringe, J. L. Dangl, and T. Mitchell-Olds, “Host genotype and age shape the leaf and root microbiomes of a wild perennial plant," Nat Commun, 2016.

[85] J. S. Patel, A. Singh, H. B. Singh, and B. K. Sarma, "Plant genotype, microbial recruitment and nutritional security," Front Plant Sci, 2015.

[86] T. R. Turner et al., "The plant microbiome," Genome Biol., 2013.

[87] K. De Roy, M. Marzorati, P. Van den Abbeele, T. Van de Wiele, and N. Boon, "Synthetic microbial ecosystems: an exciting tool to understand and apply microbial communities," Environmental microbiology. 2014.

[88] Y. Bai et al., "Functional overlap of the Arabidopsis leaf and root microbiota," Nature, vol. 528, no. 7582, 2015. 